\title{
Relevance of Authenticity in the Revival of Heritage Buildings in Cities: Insights from Bahrain
}

\author{
Ayesha Aga Shah \\ Department of Architecture and Interior Design, \\ University of Bahrain \\ Bahrain
}

\begin{abstract}
Recently, Bahrain has focused attention to the revival of historical cultural and built heritage. Bahrain's new urban projects are employing elements of heritage in the development projects in order to attract global attention and local investment whilst fostering economic growth. Cultural heritage enables people to understand previous generations and where they come from and can thereby provide an automatic sense of unity and belonging. In these developments however, issues arise related to the need to recognize and retain authenticity as an inherent value of cultural heritage.

The objective of this paper is to demonstrate how relevant or irrelevant authenticity is, in relation to promoting heritage restoration and re-development of heritage buildings. It examines how the engagement of heritage in development has incited a cultural revival within the new urban developments. The paper evaluates authentic historical fabric in the revived architecture of old Muharraq-the previous capital of the country that has undergone a renaissance of tangible and intangible heritage from the past. It critically analyses how this new built heritage is being produced.

The research employs a study of documentation of these projects, reflecting on their aims and motivations. It buttresses the analysis by the engagement of people's perceptions derived using a survey of opinions. It examines insight on how local residents relate to these renewal projects and if they do indeed promote national pride and a sense of belonging to their historic past.

In conclusion, the paper locates if authenticity is, if at all, relevant to the people's engagement with their cultural and built heritage in Bahrain. Moreover, it evaluates the ways in which the cultural revival has helped to create a sense of belonging among the people.
\end{abstract}

Keywords: Heritage, authenticity, integrity, urban development, area conservation

\section{Introduction}

Cultural heritage is a major facet of any society in providing an insight into the traditional values of a place and its people. Therefore, sustaining cultural heritage should be considered as an essential component of any development of a country. According to ICOMOs and its International Cultural Tourism Charter, "Heritage is a dynamic reference point and positive instrument for growth and change" (1999).The emerging connection of promoting urban development and accepting change is a driving force to sustain cultural heritage. However, when considering 'change' as a sustainable approach for heritage management, authenticity of historic architecture is important to be considered. The connection of authenticity that can be derived from the place, is as much as or even more important than managing change in the historic environments.

Bahrain is an island of which history dates back to Dilmun and Tylos periods. Those momentous periods gave Bahrain cultural heritage and unique history to be cherished and maintained. The historic setting, landscape and architecture of Bahrain are evidence of the rich past of that cultural heritage. Having 
the advantage of strategic geographical location with rich oyster banks in the vicinity, Bahrain in the past presented an attractive landscape and had the finest variety of pearls in the world (Olsen, 2002). Bahrain has unique tangible and intangible heritage in terms of traditional architecture, historic sites, handicraft, music, poetry, pottery etc. Alongside a number of significant historic buildings and heritage sites, the world's largest known pre-historic cemeteries are located in the land of Bahrain known as the burial mounds.

To preserve the cultural heritage of Bahrain, the first law was introduced in 1970 as the Bahrain Antiquities Act of 1970. The antiquity law was further modified in 1975, 1985 and the last version was established in 1995. Today, Bahrain is honoured to have two World Heritage Sites: The Bahrain Fort and the Pearling Testimony including 33 heritage properties in Muharraq. Along with the tangible structures, the authorities are reviving the significant intangible cultural heritage by associating these buildings with famous historical figures such as musicians, artists, calligraphers etc. For example, Kurar House has been dedicated to the cultural practices of embroidery with gold threads and Ebrahim Al Arrayed house of poetry has been dedicated to the first poet of Bahrain.

The traditional economy of Bahrain depended upon pearling, fishing and agriculture. After the discovery of oil and gaining independence, Bahrain has undergone a dramatic transformation since 1968; evolving from a collection of unplanned towns to a modern urban Kingdom. As Yarwood 2005 states,

"The urban fabric was organic and compact and evolved with time, displaying a harmony with the prevailing cultural and natural requirements. Different parts of the city were linked together by an interesting organic network of alleys and hierarchy of spaces, from public to semi public and private domains."

(Yarward, 2005:7)

Heritage is a significant concern in today's urban developments. The historic places embody the symbolic dimensions of our ancestors by their unique spatial connection with the places. The government of Bahrain has a strong vision to make the country a place for global attraction for tourism and to provide high quality of life to the inhabitants with its National Economic Strategy Vision 2030, ensuring sustainability, and promoting competitiveness and fairness. Thus, the island has recently seen an aggressive development practice that is transforming all its cities and villages. As the Kingdom is ambitious to be recognized in the world heritage industry, there is a noticeable progression in conservation and restoration projects in the development of the country as well. The pearling testimony is the best example here, not only for the heritage building restoration, but also for neighborhood preservation and development. Due to its nomination as a World Heritage Site, the government is developing supportive infra-structure and tourist stations. The revitalization of the old houses in Muharraq is a positive input towards urban development. To some extent, the private sector is struggling to portray the traditional style buildings in the new urban projects, although it is debatable when considering authenticity.

The Ministry of Municipalities Affairs and Urban Planning and the Bahrain Authority for Culture and Antiquities are both providing extensive services to promote urban development and heritage uplifting, simultaneously. However, there appears to be a lack of coordination between these instrumental forces. For example, neither of the departments has a policy or guidelines to work in collaboration with the other. The planning department does not seem to consider heritage properties in the Urban Master Plans. Likewise, the Authority for Culture is not coordinating their future interventions at the urban development scale with the planning department. There is also a gap in the documentation and recording of any heritage initiative taken to promote urban environment. For example, there are no visible policies in the Vision 2030 addressing the promotion of cultural heritage.

\section{Research Issues}

This research focuses primarily on urban development and heritage management. Continued growth of cities in the global south has led to the creation of 'mega cities' in many of the developing countries. When such growth takes place, historical buildings are often marginalized and retaining cultural heritage while promoting urban growth is one of the key challenges for any sustainable development. Such developments must balance the two extreme situations. One is to preserve the vernacular settings that bestow identity to places and retain authenticity of the past, and the other is to promote modernity, which integrates authenticity of the present. 
Heritage management parallel to rapid urbanization is a big challenge globally. Bahrain evolved from the people-driven domestic settlement of neighbouring Arab regions to a modern 'Megapolis' from people coming to work there from almost around the world. Due to modern urbanization, the historic outlook of the cultural heritage of Bahrain is diminishing. The increase in population, land reclamation, traffic congestion and transportation are threatening the socio cultural environment.

This paper is based on two hypotheses as follows.

1. There is a lack of area conservation and a focus only on buildings.

2. The re-establishment of authenticity of the heritage buildings and heritage architecture is essential in the preservation of cultural heritage.

\section{Authenticity}

The significance of heritage buildings lies in its degree of authenticity. For assessment of authenticity, four criteria were introduced by the World Heritage Committee (1978) including 'design', 'materials', 'workmanship' and 'setting'. However, the importance of the use of authenticity criterion for guiding decisions after the registration process was first stressed in management guidelines of UNESCO and Feilden for the World Heritage Sites (1993), titled as 'Authenticity and Treatment' (Nezhad, et. al.,2015). Soon after, the idea gained more attention in the Nara Documents of Authenticity 1994. For the first time, it recognised authenticity of the intangible cultural values relative to tangible heritage. To access the measure of authenticity, the World Heritage Convention 2005 presented criteria for articulating 'Test of Authenticity' with both tangible and intangible parameters (UNESCO, 2005).

It is argued that authenticity criteria for assessment of heritage buildings is similar to the criteria of 'Listed Building' for listing the special interest heritage buildings. Both criteria justify the value of a building as 'heritage' building. The main difference here is perhaps the reason of nomination of the heritage properties in the government list to legally protect heritage from the unsympathetic developments or alterations. Another reason could be the detailed associated measures with the property. For example, the particular merits for the Listed Buildings in England are distributed into four categories, such as architectural interest, historic interest, close historical association and group value (Mynors, 2006), which justifies its value more deeply.

The criteria for measuring 'authenticity' of heritage buildings can be derived through the studies of some international authenticity criteria examples, critical theories by experts and finally the understanding of local community perceptions about authenticity. The intention here is not to define the detailed criterion, which itself is a complete separate research. However, the research contribution here is to establish a basic comprehensive outline for the criterion at a rationale level (Refer Table 1and 2). The outline criteria set mainly two merits; Tangible Evidences and Intangible Evidences. It is further sub divided into five parameters to separately calculate the authenticity level of individual heritage buildings.

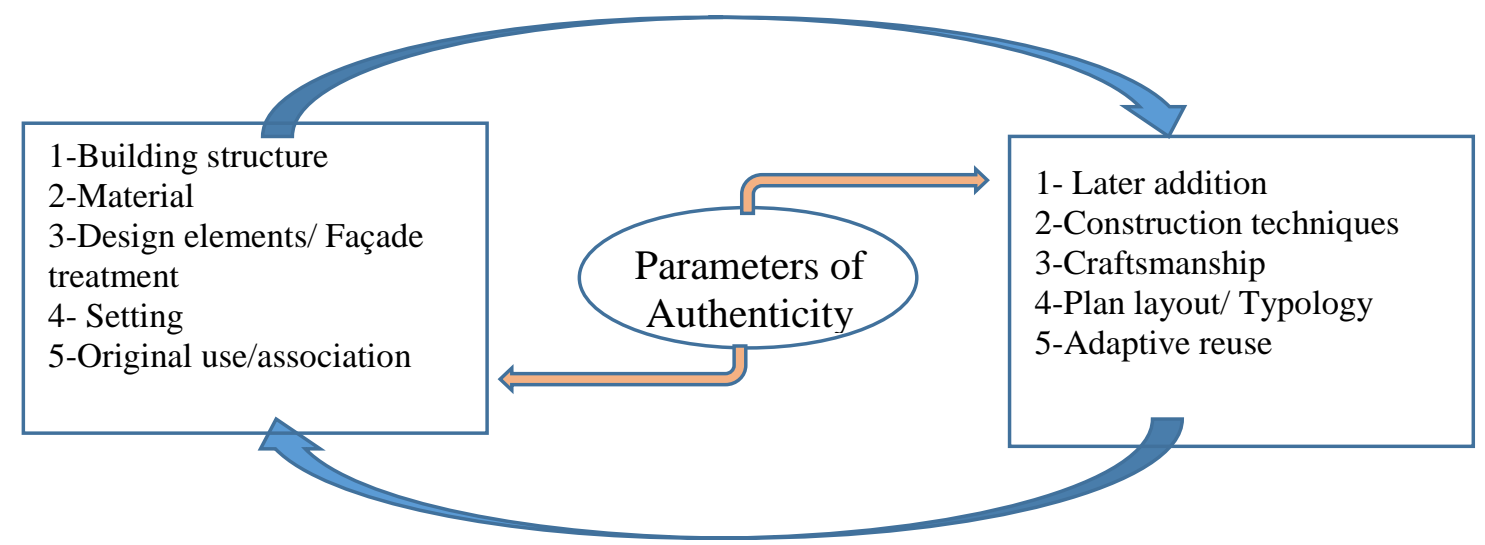

Fig. 14: Proposed merits of authenticity Source: Author 
To establish a general understanding of the level of authenticity, this paper proposes a procedure whereby each criterion can be allotted with certain points. To calculate the level of authenticity in a comprehensive way, every criterion is allotted 10 points. Each tangible and intangible evidence has the potential to be assessed out of 100 points altogether (Refer Table 1.3).The intention is to use these authenticity criteria and assess the level of authenticity in a number of heritage buildings. This assessment of the authenticity criteria however is based on the author's understanding. Therefore, it may or may not measure the actual level of authenticity, which may require extensive research involving people.

Table 1: Proposed Authenticity Criterion for Tangible Evidences Source: Author

\begin{tabular}{|l|l|l|}
\hline & \multicolumn{1}{|c|}{ Tangible evidence } & \multicolumn{1}{c|}{ Brief description } \\
\hline 1 & Building/Structure & Physical status of the building; maintained/ partially maintained \\
\hline 2 & Material & Quality and variety of materials \\
\hline 3 & Design elements/Façade treatment & composition of architectural features and detail of ornamentation \\
\hline 4 & Setting & Physical environment within , and with surrounding properties \\
\hline 5 & Original Use/ association & The continuity of original uses \\
\hline
\end{tabular}

Table 2: Proposed Authenticity Criterion for Intangible Evidences Source: Author

\begin{tabular}{|c|l|l|}
\hline & \multicolumn{1}{|c|}{ Intangible evidence } & \multicolumn{1}{c|}{ Brief description } \\
\hline 1 & Latter addition (if applicable) & Any alteration subjected to mass added, mass subtracted etc. \\
\hline 2 & Construction techniques & $\begin{array}{l}\text { Unique construction techniques which may be common or rare in } \\
\text { historic buildings }\end{array}$ \\
\hline 3 & Craftsman ship & $\begin{array}{l}\text { the manner people have fashioned to build for functional and } \\
\text { ornamental purposes in particular culture }\end{array}$ \\
\hline 4 & Design Layout/ Plan Typology & $\begin{array}{l}\text { composition of design elements, principles and spatial organization of a } \\
\text { property }\end{array}$ \\
\hline 5 & Adaptive reuse (if applicable) & Current use/ dedicated to someone \\
\hline
\end{tabular}

Thus the objectives of the paper are as follows.

1. To demonstrate that there is a lack of area conservation and an excessive focus on buildings, which is counter-productive as a strategy for heritage conservation in Bahrain.

2. To demonstrate that the re-establishment of authenticity of the heritage buildings and heritage architecture is essential in the preservation of cultural heritage in Bahrain.

\section{Theoretical Basis}

There is plenty of literature dealing with urban development and heritage management. Among them, two approaches are prevalent. One is to preserve the vernacular settings that bestow identity to places and retain authenticity of the past, and the other is to promote modernity, which integrates with the authenticity of the present. Beyhan (2015) discusses this differentiation in terms of 'urban identity and urban transformation' while discussing the situation in Turkey. The globalized urban transformations are taking place all over the world, often leading to reshaping of the cities. Undeniably, identity is as important as progression, which locates people and place. Absence of such a position is clear in the recent developments in Dubai. In fact, simply continuing with existing buildings alone does not yield such outcomes either. As Dayaratne (2014) citing Colquhoun (1996) says, 'imagined continuity' of the past to practice 'historicism' depends on ideology, hence may or may not construct identity.

In view of these transformations, Khalaf (2000) describes rapid growth and uncontrolled urbanization pressure as an 'alarming' situation "where new construction is sometimes designed and built in a manner that threatens to diminish heritage values". She argues that such diminishing leads to the loss of an important veneer of identity of a people that can only be brought from the past. However, Jokilehto points 
out that, "identity, on which the values and the individual 'personality' of a particular culture are based, cannot be defined in isolation. Cultural characteristics obtain 'contacts and interaction' influences regeneration over the time" (2006). Thus, the flavour of different cultures combine and place the identity and setting of particular time and generation. This continues the cycle of integrity, reform the variety and create a veneer of collectiveness.

Moreover, overlapping ideas of multi-layers has the ability to contribute to a unique identity on its own. It does not reflect only the heritage of one individual building, rather the setting of the masses through other elements such as trees, thoroughfares and common public places. It also reflects the idea of 'transformation' and justifies 'identity' over time. This overlapping can come also from different times. Jokiletho elaborates on the idea of diversity, "Each generation should re-generate the values inherited from the past, and re-interpret them reflecting the notion of cultural diversity. Sometimes such re-interpretation took place in new situations, therefore calling for change" (2006:7).

Hence the concept of area conservation is significant in the protection of historic settings in new developments. The Bura Charter (1979) highlights the 'understanding of the significance of a place' instead of just monuments and sites. The importance of area conservation is further rationalized in the Washington Charter (1987), which emphasizes that the social and economic development policies should be integrated with historic town and urban area conservation. UK with its rich historic architecture and modern development stands protective and productive. The planning policy statements and guidelines of UK define sustainable urban design and manage the preservation of historic areas. The strong and developed concept of 'Conservation Area Designation' ensures the identity of the heritage setting and promotes the diversity in the new urban design (PPS1)

Literature dealing with cultural heritage and management of conservation practices in Bahrain is somewhat limited as the conservation practices are relatively new. There are only two complete restorations of monumental heritage of archaeological and architectural sites like Arad Fort and Qalat-al-Bahrain. As El Habashi (2014), citing UNESCO (2005) states that the Qalat-al-Bahrain restoration was quite unprofessional considering the "much beyond the acceptable according to the professional ethics after 1987, which makes the identification of the authentic remains difficult."

Historic documentation and research on national identity and tangible and intangible cultural heritage give some background of the authentic heritage status of Bahrain. For example, Olsen (2002) who highlighted intangible cultural heritage of Bahrain added interesting information on the traditional music of Bahrain. Yarwood (2005) illustrates and documents the architectural heritage of Bahrain, particularly old houses of Muharraq. Dayaratne discusses vernacular heritage identity and tourism development. Moreover, El Habashi (?) evaluates the feasibility of the seven basic principles of ICOMOS Ename Charter (2008) of the 'Interpretation and Presentation' of the 'Seyadi Shops' in Muharraq. This evaluation practice based on the international charter perhaps is an optimistic starting point to manage change and support the idea of 'authenticity'. However, by looking at the other side of the coin, the particular selection of more subjective and flexible Charters like the Ename Charter in this case, leaves the question of 'authenticity' subjective in the conservation practice of Bahrain.

The notion of Authenticity was first mentioned in the Venice Charter, (1965) in its preamble while describing the safeguarding of the monuments with its full richness and 'authenticity'. It further emphasized on restoration with respect to the 'original material and authentic documentation'. Later on, the subject received serious and measured attention in the area of heritage conservation. The deliberate debate on authenticity moved further from the materialistic tangible approach of heritage buildings to the intangible sprit of a culture and place. For example, the World Heritage Committee (1978) identified four criteria; design, materials, workmanship and setting for the assessment of authenticity, whereas, the Nara Charter 1994, moved the concept from buildings to 'cultural diversity'. Jokilehto (2006) and Stovel (2007) elaborate the idea of 'authenticity' by discussing the examples of eastern and western consideration of heritage values and integrity, which may vary from culture to culture and overtime.

NARA is a significant document that deals with Authenticity. It points out that 'authenticity judgment' mostly depends on the cultural context and the availability of information such as "form and design, materials and substance, use and function, traditions and techniques, location and setting, and spirit and feeling, and other internal and external factors" (Article 13). Moreover, Alho, C., et.al. (?) propose five parameters to assess authenticity such as "materials, design, workmanship, function and setting". These provide a comprehensive set of criteria in terms of two separate dimensions of tangible and intangible 
evidences. In fact, this segregation of two categories helps in ascertaining more specifically each heritage content instead of viewing it generally as reviewed in literature. This theoretical understanding can practically contribute in managing cultural heritage in the revival of heritage buildings in cities.

\section{The Research}

This paper investigates if conservation of individual buildings alone is sufficient to preserve the heritage of a place. It ascertains if and how the sense of belonging, memory and recognition in the promotion of urban development contribute integrity in the continuity of 'authenticity'. It initiates this by establishing the links between urban development and heritage development in Bahrain; specifically how it affects the rebirth of the old area of 'Muharraq'. The theoretical framework on area conservation and authenticity of a place presents this understanding. It then examines how heritage conservation satisfies people's perception in the new developments. The paper thus contributes to the establishment of the basic criterion to assess the level of authenticity achieved in the restored buildings of Muharraq, which can be used in future research. At the end, the paper concludes with the public views about the revival of historic area of Muharraq, which will ascertain if the present conservation practices are sufficient to preserve the heritage of place.

\section{Research Methodology}

This research employed documentary research as its main methodology. Further, data was also collected through structured and semi-structured interviews, observing cultural practices and by surveying the area of Old Muharraq.

- Documents were analyzed in the light of the explicit definitions.

- Architectural documentation and historic images, sourced from literature were compared with material generated by surveying the sites. Some of the information were provided by the owners or caretakers of the buildings.

- The research conducted survey of opinions, divided into two categories, for the following purposes.

i- $\quad$ To explore the people's understanding about heritage conservation. Six semi-structured interviews were conducted among government and private sector employees. This method explored the professional voice of those who are involved in the management of heritage.

ii- To explore the perception of people regarding heritage buildings of Muharraq. Fifty structured interviews were conducted from the people of Bahrain. This was aimed at the perception of people on authenticity; people of Muharraq experience this heritage building very closely, and the changes of the surrounding neighborhood matters in their everyday life.

- An adapted historical building, from an old house to an art gallery was visited in order to evaluate its heritage features against the criteria (See appendix 1). The owner of the site provided verbal information, but was unable to present any documentary materials. This lack of information on pre and post building plans restricted the intended evaluation of authenticity of the site.

- Visits were made to Muharraq at different timings in order to establish a thorough understanding of the old area. Three locations were explored to understand developments within the main historic core of Muharraq, Block 209.

\section{Findings \\ Hypothesis 1: Lack of area conservation and a focus only on buildings:}

In the understanding of the conservation activities in Bahrain, the Authority of Culture has made efforts and conserved a number of individual buildings in Muharraq. However, the public places around them have transformed themselves through organic growth, changing the unique character of the area. The Authority has initiated re-designing of these public places or squares for the rehabilitation of the area. Nevertheless, the design reflects more of a modern urban approach than the historic understanding of the area. They can be seen in the following observations, with the conclusion that the approach to building conservation is losing the sense of 'setting' of the historic areas, especially in Muharraq. 


\section{The case of Block 209, Old Muharraq}

Block 209, Muharraq is a good example of old buildings of architectural and historic interest. It also comprises a group of buildings, restored by the government and the private sector. This research discusses three locations and shows the impact of new development that has damaged the character of the historic zone.

\section{The Area around Abdulla Al Zayed Press}

Fig.1 shows the important heritage building of Abdulla Al Zayed Press and its extension. The details show two different architectural vocabularies of different times next to each other. As Sulati points out, "The modernization of traditional houses and construction of new buildings to provide low cost housing for Bahraini lower or middle classes is causing a major serious challenge for the conservation of the historic urban architecture" (2009;51)

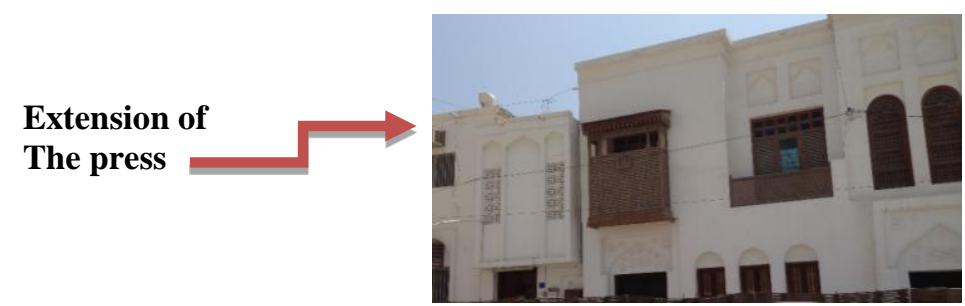

Fig. 1: Abdulla Al Zayed Heritage Press and its extension Source: Author

The new buildings surrounding three sides of these houses are completely out of context, in terms of architectural design and the use of fabric. Therefore, it is indeed important to device a planning policy to protect the historic setting, to assert control on the unsympathetic new development in a historic site.

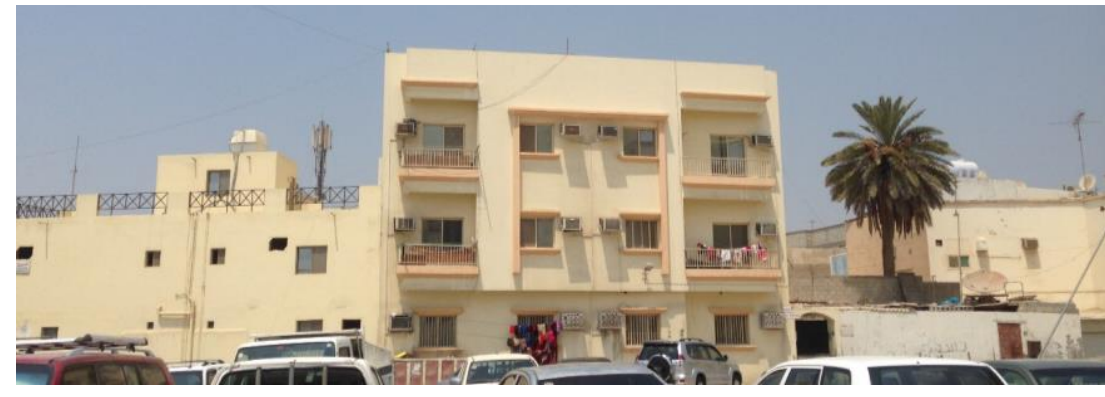

Fig. 2: Left side of Abdulla Al Zayed Heritage Press Source: Author

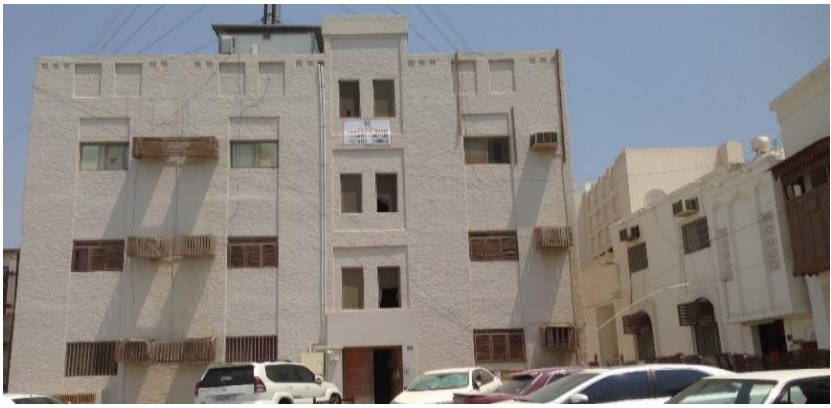

Fig. 3: Right side of Abdulla Al Zayed Heritage Press Source: Author 


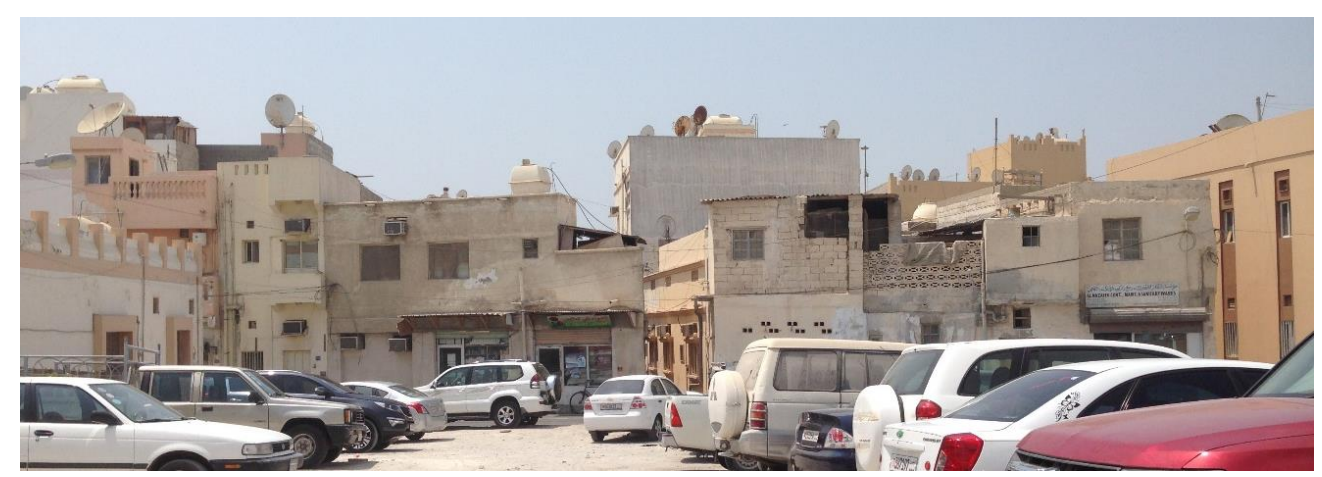

Fig. 4: Front side of Abdulla Al Zayed Heritage Press Source: Author

\section{The Case of Sh. EbrahimCenter:}

A number of public squares have been constructed among the setting of old buildings, with an alien design approach without considering the social pattern of the place. The historic pattern of roads defines the social movement of the community. As Yarwood points out, "These seems to be neither an engineering pattern, nor physical or material hierarchy. The pattern is social in nature" $(2005 ; 16)$. There is no context of these concrete designs within the dedicated soft urban fabric. It shows a serious insensitivity to the historic urban setting and calls for a more holistic approach to area conservation.
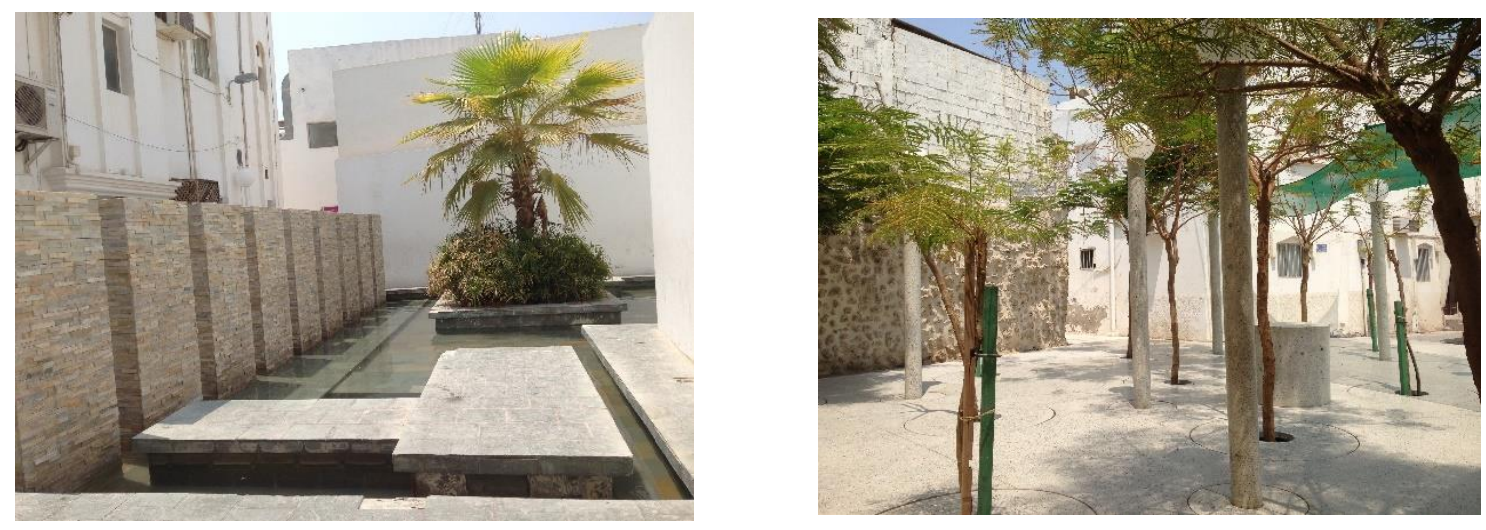

Fig. 5 and 6: Unsympathetic development of historic public squares Source: Author

2. Authenticity: Integration of heritage buildings and styles with new urban development often create conflicts of place identity. The heritage development in Bahrain can be described by three categories as follows

2.1: Heritage buildings built or restored by the Cultural authority: The department claims for the authentic conservation/restoration followed and adopted by the international charters such as AmaratFakhro (Fig. 7\& 8) and MadarsaEl Hedaya (Fig. 9), with minimum interventions. 

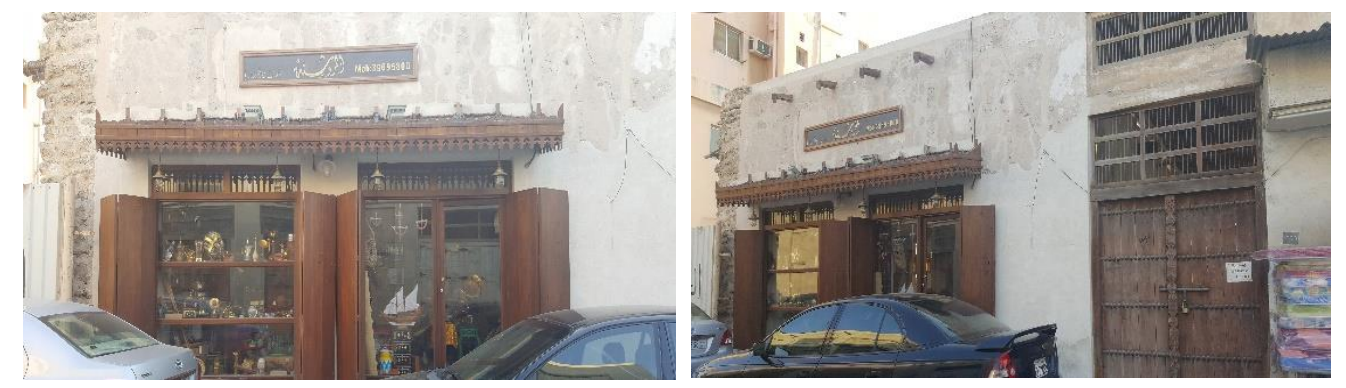

Fig. 7 and 8: AmaratFakharo

Source: Author

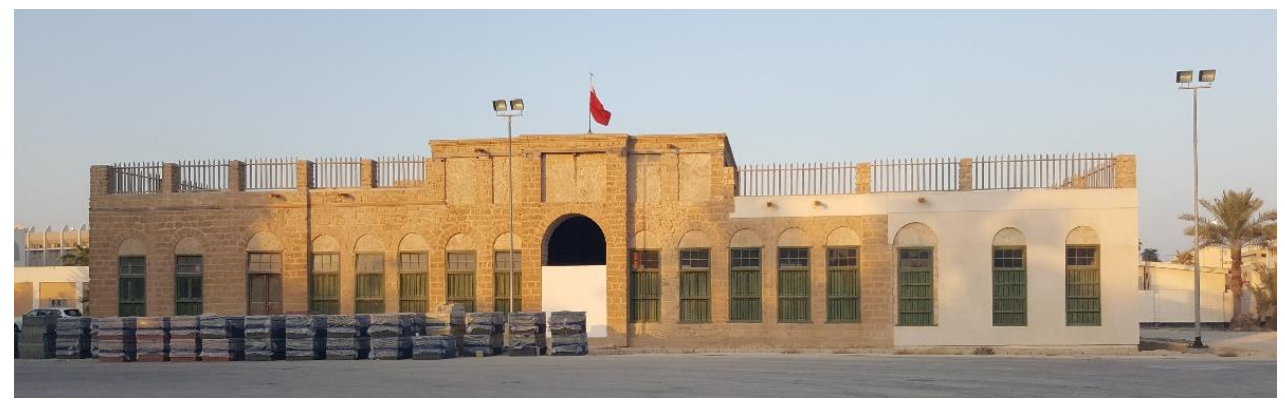

Fig. 9:Madarsat El Hayat

Source: Author

2.2: Heritage buildings done by the private sector: The original structure is often missing (varies in buildings from $20 \%$ to $70 \%$ ) and rebuilding as the continuation of the existing structure, which is more likely new redevelopment rather than restoration. Example, Busaad Art Gallery (Fig. 10\& 11)
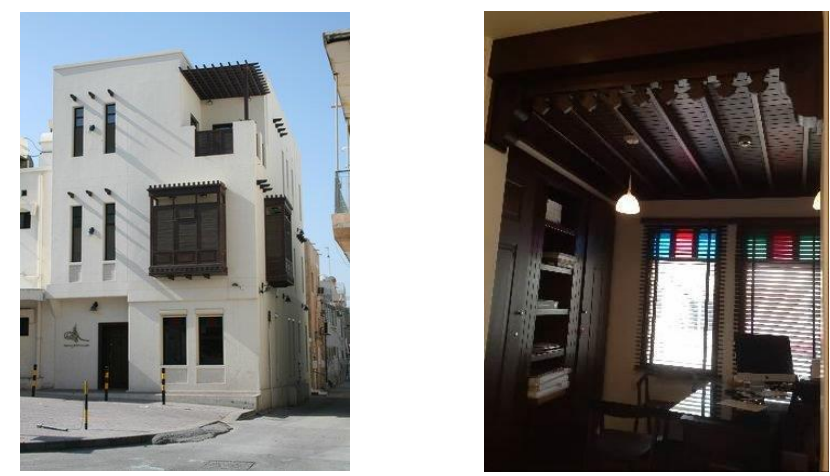

Fig. 10 and 11:Busaad Gallery, exterior and interior Source: Exterior - Busaad Gallery official site, Interior - author

2.3: New buildings done by stakeholders: Using heritage-building elements in new construction, for example Novotel Hotel (Fig. 12) and Dyar AlMuharraq. Here the status of authenticity is debatable whether it comes in the category of pastiche or integrity. 


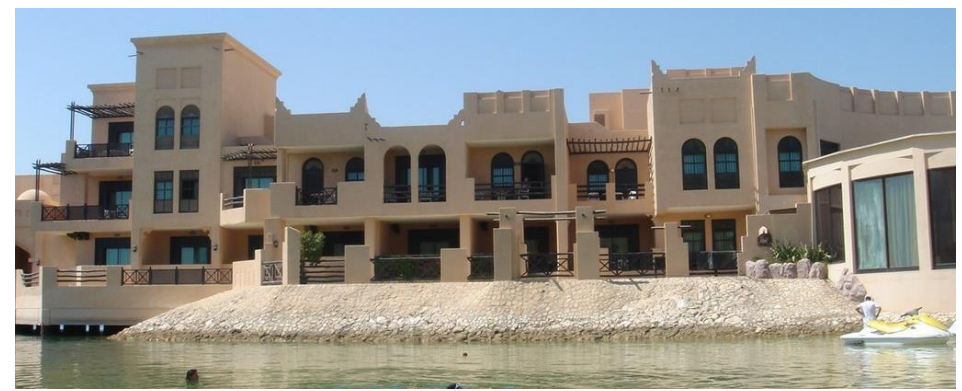

Fig. 12: Novotel Hotel

Source: www.yumsafar.com

The example of Novetel hotel best reflects the hypothesis-1. The hotel is located in the vicinity of old area Muharrq. The surrounding of the hotel is developed with a new built environment which is completely against the historic language of architecture. The heritage appearance is imposed as counter-productive strategy for heritage conservation in Bahrain where the superficiality of historic building features are presented. The above cases substantiate the hypothesis 1.

Hypothesis 2: That authenticity of the heritage buildings and heritage architecture is essential in the preservation of cultural heritage in Bahrain

The research outcomes to ascertain this hypothesis are divided into three parts. In the beginning it gives an introduction about Muharraq with its historic and cultural significance. It further demonstrates how tangible and intangible heritage renaissance has taken place in recent times. This rebirth of the old heritage style will be critically discussed with the example of one heritage building, restored by the private owner. The first part of research outcomes includes discussion of some semi-structured interviews to understand the professional practice of building conservation in Muharraq. It also includes survey of opinions from people of Muharraq about the significance of the historic area, and its key findings. The second part assesses the relevance of authenticity in the heritage buildings of Muharraq.

The third and last part critically analyzes one of the old areas of Muharraq, block 209. This area is purposefully selected to show the neighborhood area around the restored buildings of Muharraq. Finally it aims to show the threat level due to the developments that do not relate well, which would lose the essence of the place if not preserved.

\section{Muharraq- an introduction:}

A former capital of Bahrain in the $19^{\text {th }}$ century, Muharraq has a significant value due to its historical and cultural background. The area still reflects the old picture of Arabian city with its traditional Arab Gulf style fine architecture with low rise buildings and narrow streets. The history and literature describes Muharraq as the first settlement of Bahrain. (Al Sulaiti, 2009) The ruling family Al Khalifa made Muharraq as their political centre and built their palaces, mosques, administration, political patronage and upper class social life (Alnabi. 2009). The development of Muharraq shows strong unity between cultural and built environment by interacting social, spiritual, cultural, religious, economic and physical requirements (Yarwood, 2005). With functional and economic values, the building of Muharraq also reflects many intangible cultural symbols and meaning. A very good example here is the Pearling Route; including some of its heritage buildings. This project has been recently nominated as the World Heritage Site in 2012.

"The site consists of seventeen buildings in Muharraq city. Three offshore oyster beds, part of the sea shore and the Qal' at Bu Mahir fortress on the southern tip of Muharraq Island, from where boats used to set off for the oyster beds. The Listed Buildings include residence of wealthy merchants, shops, storehouse and a mosque. The site is the last remaining complete example of the cultural tradition of pearling and the wealth it generated at a time when the trade dominated the Gulf economy"

(UNESCO, 2012) 


\section{Renaissance of Old Muharraq}

The old area of Muharraq has undergone a renaissance of tangible and intangible heritage from the past. In its cultural and heritage revival, Bahrain Authority of Culture, under the supervision of $\mathrm{H}$. E. Shaikha May, is conserving old houses of Muharraq.

"Each rehabilitation house tells a story of Bahraini culture by a sensitive and innovative functional adaptation either to reflect the occupation of the original owner (music, press, pearl, poetry) or to revive traditional crafts (embroidery, fishing, culinary) or to promote cultural and social activities"

(El Masri \& Dayaratne, 2016: 9)

It is interesting to observe that the growth pattern of these rehabilitated houses is quite organic. (Fig 00?); , it does enhance the group value of the buildings.

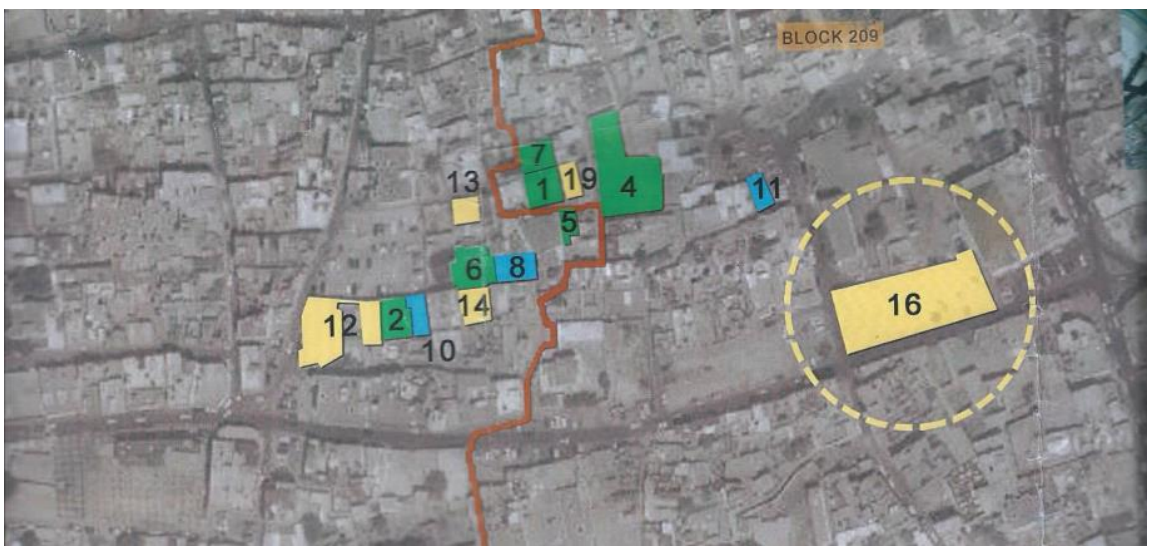

Fig. 13: Old Area of Muharraq, Block 209

Source: El Masri \& Dayaratne, (2016)

One reason of this rehabilitation process is to bring back the old natives residents of area, who rented out their houses to non-Bahraini expatriates of lower income social class. It is important to note here that people prefer to reside in the new capital Manama or other developed areas, as these offer better infrastructure and convenient life styles. The rehabilitation project of old Muharraq displays itself as a living museum with the conservation of tangible heritage, old houses, and revival of the intangible values. Each restored house is nominated to their original owners' occupations where traditional cultural activities such as music, poetry reading and arts and crafts are practiced regularly. The project comprises the ongoing reconstruction and reuse of historic houses. "Restoration is complemented by the strategic use of modern materials although all finishes are traditional, reviving local construction techniques" (The Aga Khan Trust for Culture, 2011).

\section{The case of Busaad Art Gallery}

One interesting example of the building restoration in this context is Busaad Art Gallery, adapted by the private owner. The gallery is associated with one of the famous Bahraini artists; Ebrahim Mohammed Busaad. The building had the typical courtyard design and was used to be a family house. The artist renovated the building in 2012 and opened it for the public in 2014. The building is situated at the corner plot with the visibility of two facades. The exterior and interior design reflects traditional Bahraini style. The question raised here is that; what is the relevance of authenticity in this particular building scenario. Is it authentic because of the reflection of typical traditional Bahrain style, or, is it unauthentic because the building renovated design is not the actual design of the building, just a showcase of Bahraini style. Most critically, the building had a central courtyard which is completely closed to meet the requirement for the proposed art gallery. The design shows neither the original layout nor the historic functional use. However, 
if authenticity here is to maintain the historic style, the building may come under authentic category; the relevance is subjective.
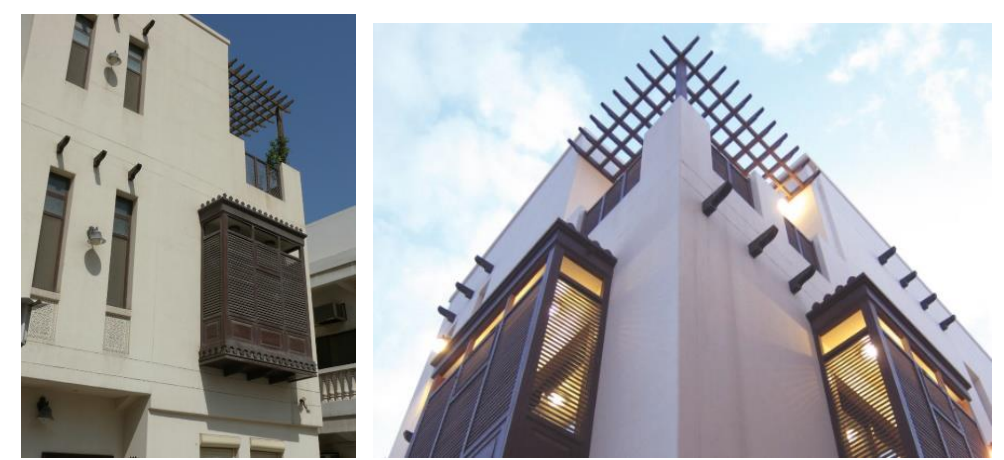

Fig. 15 \& 16: Busaad Gallery, Exterior Details

Source: www.yamsafar.com
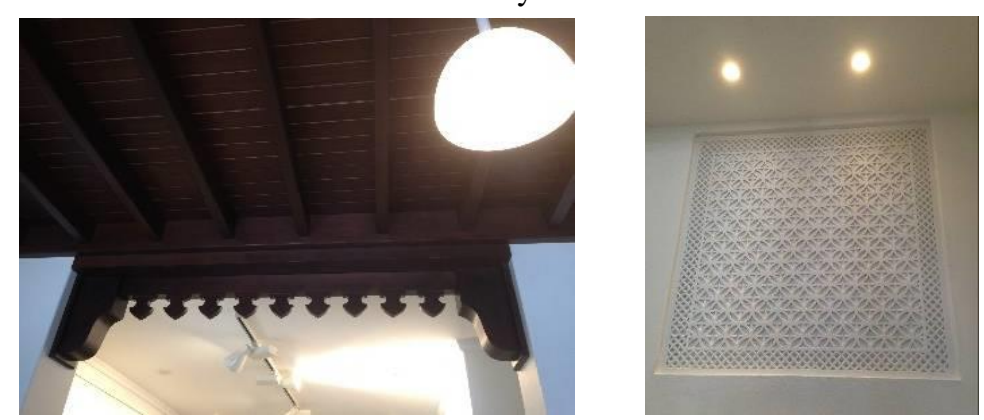

Fig. 17\& 18: Busaad Gallery, Interior Details Source: Author

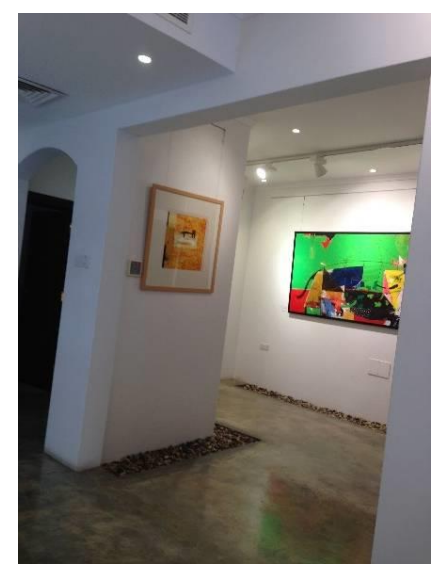

Fig. 19: Busaad Gallery, the covered courtyard for the display of the art Source: author

\section{Summary of key findings on relevance of authenticity} Survey of opinion: Semi structured Interviews from six participants

According to the feedback from the government sector, the conservation practice is adopting a specialist approach by following international guidelines. Dealing with WHS, the Statement of Conservation (SoC) reports submitted to the UNESCO shows the informed conservation for the restoration 
of such buildings. For example, in the project of pearling testimony, Nukuda House and Al Ghouse house show quite satisfactory status in line with conservation rules. The detailed documentation and technical reports are available to evaluate the status. The government is taking initiatives for raising public awareness, about built and intangible heritage, such as promoting music and other traditional arts. For instance, the BACA dedicated the year 2015 as 'Our Year of Heritage' and 2016 as the 'Spring of Culture 2016' to celebrate history as a reminder of cultural identity and belonging.

The outcome of six semi-structured interviews with the government and private sector were somewhat contrasting. Different points of view were presented: Two participants related authenticity to respecting the exterior design in term of façade treatment by replicating historic building elements, such as similar colors and patterns to harmonize the environment in the old styles. Three participants emphasized on commercial value of recreating heritage style designs to provoke nostalgic memories of the past and attract locals to promote business.

\section{Survey of opinion: Structured Interviews from fifty participants} Muharraq.

Interviews results show the following opinions from people regarding the heritage buildings of

1. $62 \%$ agree that historic heritage in Muharraq has good physical status.

2. $88 \%$ are in favor of protection of heritage building within new development.

3. $64 \%$ support the new development in historic area.

4. $73 \%$ agree with the sense of belonging with heritage buildings.

5. $29 \%$ cannot differentiate between heritage buildings and the newly developed buildings in heritage style.

The most interesting response was received on the question of relevance of authenticity. $35 \%$ people agree that authenticity is relevant whereas, $25 \%$ disagree. It is interesting feedback that almost $45 \%$ people support the relevance in the absence of nothing; in their opinion the restored buildings add to the atmosphere and somewhat reflects the past.

\section{Conclusions}

This research sought to test two hypotheses. They were that;

- There is a lack of area conservation and a focus only on buildings.

- The re-establishment of authenticity of the heritage buildings and heritage architecture is essential in the preservation of cultural heritage.

Both hypothesis were substantiated by the research. The paper acknowledges that the old town of Muharraq has a significant position within the history of Bahrain. The research intended to gain insights of the local residents' perception of heritage buildings and their conservation. Analytical reviews on peoples' awareness of the relevance of authenticity reflect sufficient engagement. This can be observed from the structured interviews where $73 \%$ people agree with sense of belonging with the cultural heritage. It is interesting here that even without knowing what exactly historic architectural authenticity is, people clearly relate to the historic symbolic meaning of their built heritage. As per the survey’s findings, $71 \%$ residents of Muharraq can differentiate between heritage buildings and the newly developed buildings in heritage style. Hence, it is essential to consider the authentic conservation when dealing with heritage buildings

The government aspires to promote Bahrain's history and culture in the global heritage industry and promotes heritage development with urban developments. The approach to promote cultural revival can be understood from the interviews of government officers. Where Shaikh Isa Centre is promoting intangible cultural heritage, the privately restored houses have their own strong impact of the traditional built heritage buildings. However, there is no deliberate study examining the preservation of the historic setting of Muharraq. The main focus is on the individual listed buildings for conservation and not considering the locality, as a whole, for heritage protection. This can be seen in the project of pearling testimony where focus is mostly on the 33 heritage properties designated by the government. However, the neighborhood of 
these heritage buildings represents the local addition to the built environment. It is vital to extend this policy to protect these neighborhoods with the concept of area conservation.

This research however had some weaknesses. First, there is a lack of access to literature: most literature is in Arabic and Policy of the Ministries on archived documents control access. Secondly, it is hard to obtain the general understanding of government's point of view: The promotion of new development with consideration of the conservation of heritage buildings is considerably limited due to poor coordination between both concerned departments. Moreover, the most important evidence to check authenticity; the architectural documentation of the restored heritage buildings was not available due to copyright or confidentiality issues. People were more open for the verbal descriptions, while being reluctant to provide official documentations. It thus acknowledges that there are significant limitations to this research. It is therefore suggested that further in-depth studies related to this context is carried out to ascertain this conclusively.

\section{References:}

Alho, C., Morais, A., Mendes, J. \&Galvão, A. (?), Authenticity criteria in conservation of historic building, http://www.irbnet.de/daten/iconda/CIB18871.pdf

Al Nabi, M. N. (2012), The History of Land use and Development in Bahrain, $1^{\text {st }}$ edn, Information Affairs Authority.

Al Sulaiti, A. (2009), Muharraq City: A GIS-based Planning Strategy for its Ancient Heritage Conservation, unpublished $\mathrm{PhD}$ Thesis submitted to University of Portsmouth, UK.

Beyhan, G. and Gürkan, U (2015), Analyzing the relationship between urban identity and urban transformation implementations in historical process: The case of Isparta, International Journal of architecture Research, Vol-9, Isuue 1

Dayaratne, R. and El Masri, S. (2016), 'Heritage Tourism and sustainability challenges and Opportunities in the case of Bahrain', Proceeding of $4^{\text {th }}$ International Architectural Conference, Dubai.

Dayaratne, R. (2016), 'Re-dignifying vernacular for constructing national identity: Elitism, grand traditions and cultural revival in Bahrain', ITU A|Z, Vol-13, no.1, pp 127-138

El-Habashi, A. and Battis, E. (2014), 'Architectural Conservation as a Means for Site Interpretation and Presentation - Case Study: Recent Architectural Conservation Practice in Bahrain, Proceeding of World Heritage Studies. BTU Cottbus, Germany.

Hassan, F. Trafford, A. and Yousuf, M. (2008) Cultural Heritage and Development in the Arab World, Special Isuue: The Contemporary of Built Heritage, Alexandria, Egypt : Bibliotheca Alexandrina.

ICOMOS (2012), Evaluation of Nominations of Cultural and Mixed Properties to the World Heritage List, ICCROM Report of the World Heritage Committee

Jokilehto, J. (2006), 'Considerations on authenticity and integrity in World Heritage context', City and Time Vol-2, no. 1

Mynors, C. (2006). Listed Buildings, conservation areas andmonuments, $4^{\text {th }} \mathrm{edn}$, London: Sweet and Maxwell

Nezhad, F., Eshrati, P. and Eshrato, D. (2015), Definition of authenticity concept in conservation of cultural landscapes, International Journal of Architectural Research Vol-9, Isuue 1.

Olsen, R, (2002), Music in Bahrain, Jutland Archeological Society, Moesgaard.

Roha W. Khalaf (2015), The reconciliation of heritage conservation and development: the success of criteria in guiding the design and assessment of contemporary interventions in historic places, International Journal of Architecture research, Vol-9, Issue1, pp.77-92

Stovel, H. (2007), 'Effective use of authenticity and integrity as World Heritage qualifying conditions', City and Time Vol-2, no. 3

The Aga Khan Trust for Culture, 2011, http://archnet.org/sites/6650

Yaewood, J. and El Masri, S. (2005) Al Muharraq: Architectural Heritage of a Bahraini city. Manama: Miracle Publishig.

http://www.mybahrain.net/viewtravelnews.asp?ID=1016

http://culture.gov.bh/en/theevents/FestivalsandAnnualActivities/HeritageFestival/ 